\title{
The Japan Stock Split Bubble and the Livedoor Shock
}

\author{
Youki Kohsaka ${ }^{1}$ \\ ${ }^{1}$ Center for Finance Research, Waseda University, Tokyo, Japan \\ Correspondence: Youki Kohsaka, Center for Finance Research, Waseda University, 5th Floor, COREDO \\ Nihonbashi, 1-4-1, Nihonbashi, Chuo-ku, Tokyo, Japan. Tel: 81-3-3272-6785 ext. 3022. E-mail: \\ kohsaka@aoni.waseda.jp
}

Received: February 28, 2014

Accepted: March 12, 2014

Online Published: April 25, 2014

doi:10.5539/ijef.v6n5p33

URL: http://dx.doi.org/10.5539/ijef.v6n5p33

\begin{abstract}
Livedoor, a famous Japanese IT company, experienced rapid growth through the overuse of a stock split strategy. Because of this strategy, the company faced a criminal investigation for suspicion of account rigging in January 2006. In this paper, I examine whether the Japanese stock split bubble burst not only because of system reform to make newly issued shares tradable on their ex-dates, but also because of the Livedoor shock. To explore this possibility, I evaluated data that were classified into specific categories: stock splits under the old system's conditions that prevented the trade of newly issued shares for about 50 days following the ex-date, stock splits under the new system's conditions, and news announced before and after the Livedoor shock. I estimated abnormal returns for each stock on their respective announcement dates. Results demonstrate that under the old system, trading restrictions for newly issued shares caused increases in stock prices, but the Livedoor shock stalled these increases for split stocks. These results suggest that the stock split bubble burst not only because of system reform but also because of changes in investor sentiment with regard to split stocks.
\end{abstract}

Keywords: stock split bubble, livedoor shock, investor sentiment

\section{Introduction}

In this paper, I explore the degree to which the Japanese stock split bubble burst can be attributed to changing investor sentiment due to the Livedoor shock in addition to overall system reform.

Stock splits allot new shares to existing shareholders in proportion to their current ownership and increase the total number of outstanding stocks. Typically, stock split announcements and executions do not affect the company's fundamentals or economic activities; however, stock price increases can occur in global markets on the date a split is announced and after the stock's ex-date. A stock price increase resulting from a stock split is largely an anomaly that asset pricing theory, including the efficient market hypothesis, is unable to explain. As a result, a number of researchers have sought to identify the causes of these stock price increases.

Because of the country's unique stock split system, sudden stock price increases in Japan are different from stock price increases in other nations. Until 2005, there was an approximately 50-day delay between a stock's ex-date and the date on which newly issued shares were paid to shareholders. As a result, for roughly two months following the ex-date, the total number of tradable shares in the exchange consisted of only those that were outstanding prior to the split. Until the pay-date, shareholders were unable to trade newly issued shares. Under this stock split system, unique price movements, collectively known as the "stock split bubble," frequently occurred in Japanese markets. It was not until the new stock split system was implemented on January 4, 2006 that new shares can be traded on the stock's ex-date, resolving the issues associated with the two-month delay.

Figure 1 illustrates the normalized average closing price of a split stock on the day before the split announcement between October of 2001 and December of 2005 (i.e., pre-system revision) and between January of 2006 and December of 2007 (post-system revision). In addition, to adjust the split ratios, I have multiplied the post-ex-date price by the split factor. The solid line depicts the average price of stocks that split prior to the system revision; the dashed line shows the average price of stocks that split following the system revision. Taken together, these lines communicate four characteristics of the stock split bubble. First, stock prices increase roughly $5 \%$ on the stock split announcement date, and then continuously increase. The cumulative return from the stock split announcement date until just before the ex-date is about $16 \%$. Second, stock prices increase sharply on the ex-day. Third, stock prices trend upward after ex-day, but trend downward just before the pay-date. Finally, stock 
prices remain approximately steady following the pay-date, but increase to about $18 \%$ higher than its price prior to the stock split announcement.

The dashed line in Figure 1 illustrates the average price of stocks that split after the stock split system was revised. Unlike stock splits before the system revision, the dashed line does not display the second, third, or fourth features described above. Although the stock price would largely rise on the date the stock split was announced, it would immediately decrease such that it fell below a standardized score of 100 after 10 days. Moreover, after the stock split system was revised, stock prices generally do not significantly increase. Following the stock split system's revision, stock prices demonstrate the tendency to increase slightly, and then continuously increase to a limited extent. Given this, the stock split bubble seems to have burst with the revision of the stock split system.
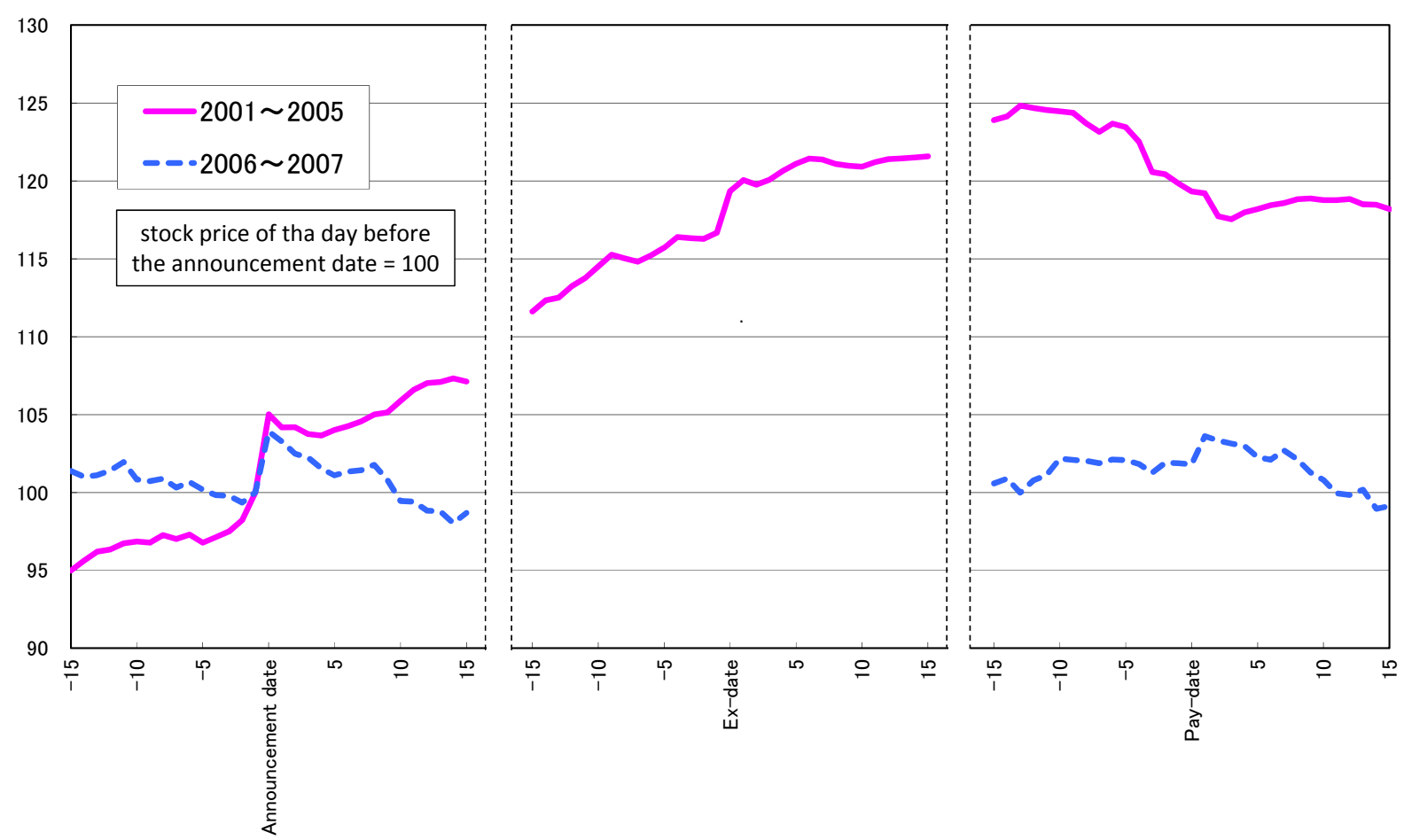

Figure 1. Average price of split stock on pre-revision and post-revision

Greenwood (2009) offered four hypotheses related to the stock split bubble in Japan. Several of these hypotheses were geared towards exploring abnormal returns reported in previous studies on stock splits. Greenwood's (2009) first prediction, which he referred to as the signaling hypothesis, suggested that a split announcement yields information about the future fundamental value of a company. Generally, the market treats stock split announcements as indicators of the company's strong future performance (Note 1). In the first empirical research on stock splits, Fama, Fisher, Jensen and Roll (1969) reported abnormal returns around the announcement date, supporting the signaling hypothesis. Other related studies have reported similar findings, further supporting Greenwood's prediction (see Asquith, Healy, \& Palepu, 1989; Lakonishok \& Lev, 1987; McNichols \& Dravid, 1990).

Greenwood's (2009) second hypothesis was referred to as the liquidity hypothesis. This hypothesis predicted a positive relationship between the number of investors in a stock and that stock's prices. When a stock splits, its price falls because the number of shares outstanding increases, thereby facilitating trading among small traders. Increase in the number of investors, however, effectively diversifies risk, thereby allowing a rise in stock price. Merton (1987) constructed model of capital market equilibrium with incomplete information. This model indicates that an increase in a firm's investor base increases that firm's value. Amihud, Mendelson, and Uno (1999) analyzed reductions in the minimum trading unit of Japanese stocks and also found that stock prices tend to appreciate in accordance with increases in the number of investors. Finally, Guo, Zhou and Cai (2008) showed that stock splits tend to enhance market liquidity in Japan. 
The third hypothesis, known as the illiquidity discount hypothesis, relates to decreases in liquidity until newly issued stocks are tradable. This hypothesis predicts that stock prices will decrease when stock splits are announced because investors require a premium for liquidity reduction and non-tradable new shares from ex-date to pay-date. This prediction is largely consistent with Amihud and Mendelson's (1986) prediction that stock illiquidity is positively associated with discounts in the stock price. Because trading restrictions persist until the pay-date, stock prices tend to be lower than prior to the split announcement. This hypothesis is derived from a fully rational model in which traders require the premium for illiquidity; however, there was no support for the hypothesis, as increases in stock price did not occur from an execution of the stock split.

Like the third hypothesis, the fourth hypothesis relates to changes in liquidity caused by lags in the issuing of new shares. Unlike the illiquidity discount hypothesis, however, the fourth hypothesis (hereafter referred to as the trading restriction hypothesis) (Note 2) predicts that stock prices will temporarily rise when the number of suppliers (sellers) decreases. Until the stock split system was reformed in 2006, trading restrictions constrained existing shareholders' selling behavior.

For example, if investors feel a stock is underpriced and wish to buy, they continuously do so, even under restrictive conditions. However, in a market where investors trade only old stocks after the ex-date, investors who feel a stock is overpriced would benefit from selling their old holdings to the degree possible. Investors can also take short positions on the old stocks rather than offsetting by the newly received shares on the pay-date. However, most investors (including mutual funds, insurance companies, and small retail investors) tend not avoid taking short positions. Moreover, it is difficult to identify and utilize a counterparty from which to borrow shares once the split is announced. Given this, stock splits under the old system constrained the selling behavior of investors between the ex-date and the pay-date.

The relationship between trading restrictions and stock prices is relatively straightforward. A restricted market in which investors can sell only old stocks extracts potential suppliers of liquidity. It also increases the price impact of trade; greater investor demand for trade during the restricted period is positively associated with stock price (Note 3). In summary, the trading restriction hypothesis dictates that a stock's price will rise on the split announcement date and on ex-date, but decline on the pay-date.

Greenwood (2009) showed that the tendency for a stock's price to rise on the announcement date and ex-date and fall on the pay-date could be explained by the trading restriction hypothesis. Although he conceded that the other hypotheses may have some influence on these phenomena, he argued that they were not sufficient in explaining the pattern of returns around the ex-date and pay-date. In addition, the tendency for a stock's price to remain consistently higher than a pre-announcement stock price for a while following the pay-date is also unexplainable in terms of the trading restriction hypothesis, as trading restrictions do not affect a stock's price after its pay-date. In this study, I explore the possibility that the stock split bubble burst, particularly as defined by the fourth feature, as a result of changing investor sentiment.

This paper's first objective is to empirically evaluate the presumptions that (a) prior to the revision of the stock split system, temporary liquidity shortages caused by trading restrictions affected the stock split bubble, and (b) stock price increases caused by trading restrictions have disappeared following the revision of the stock split system. Additionally, this paper is designed to test whether the signaling and liquidity hypotheses have additional validity.

This study's second objective is to test whether the "Livedoor shock" played a role in the bursting of the stock split bubble. Livedoor, a notable Japanese IT company, experienced rapid growth as a result of overusing the stock split strategy. Specifically, Livedoor performed a 3-for-1 stock split in May of 2001, a 10-for-1 stock split in June of 2003, and a 100-for-1 stock split in December of 2003. Each time Livedoor performed a stock split, the stock's price spiked. Livedoor got an advantage when buying some companies in a stock swap using stock whose price increased due to stock splits. Following this, Livedoor became representative of the stock split bubble. The CEO of Livedoor, Mr. Takafumi Horie, was hailed as a hero of the finance markets as a result of the company's split strategies. However, on January 16, 2006, Livedoor and its associates faced a criminal investigation by Tokyo District Special Investigators for suspicion of account rigging (Note 4). As a result of the announcement of this investigation, stock prices crashed across the Tokyo Stock Market the following day and in the subsequent weeks (Note 5).

In this paper, I consider whether the stock split bubble burst not only because the stock split system was revised, but also because of the investigation of Livedoor. The latter altered investor sentiments such that split stocks were indicative of a company that was performing poorly. The cognitive association between split stocks and poor performance derived from the fact that Livedoor engaged in an extensive split stock strategy and was 
subsequently subjected to a criminal investigation. This is in stark contrast to past sentiments related to stock splits that related splits to good company performance (Notes 6 and 7). It is difficult to differentiate the effects of the stock split system revision and the Livedoor shock, as their respective occurrences were nearly simultaneous. However, I was able to collect testable data because regulations associated with the new stock split system apply to stock splits that have ex-dates after the system's revision and many companies announced stock splits one to two months before their stock's ex-date. I avoid difficulties associated with separating the effects of the system revision and the Livedoor shock by using two separate samples that are distinguished in terms of the date on which their stock split was announced - before or after the Livedoor shock.

Though I explore many of the same concepts as Greenwood (2009), this study differs from Greenwood's (2009) in several fundamental ways. First, Greenwood (2009) utilized a sample of 2,094 stock splits between January of 1995 and April of 2005. My sample is comprised of 189 stock splits between October of 2001 and December of 2007. Although my sample is smaller than Greenwood's, I utilize it in a more sophisticated fashion through the exclusion of split stocks that changed relative dividend value to stock price between the announcement date and pay-date. In Japan, even after stock splits, many companies tend to maintain their stock's dividend value (Hanaeda \& Serita, 2004). This means that an increase in dividends effectively increases the stock's price. Therefore, to verify the effect of a stock split on the stock's price, we exclude companies that announced changes in dividends between the announcement date and pay-date (Note 8).

Second, Greenwood (2009) tested only the trading restriction hypothesis. In contrast, in this study, I use simple variables to test all the hypotheses outlined above, with the exception of the illiquidity hypothesis. Third, Greenwood (2009) neglected to discuss the reasons why post-pay-date stock prices remain higher than prior to the announcement of a stock split. This cannot be explained by the trading restriction hypothesis because under the old system, prices of stocks that split remain high over the long-term despite the absence of trading restrictions following the pay-date. I believe this is an essential feature of the stock split bubble in Japan and suggest that investor sentiment towards split stocks caused the emergence of the bubble; this sentiment (as well as the bubble itself) disappeared as a result of the Livedoor shock. Using a sample of observations related to stock splits (including after the rule revision), I test the three hypotheses described above, as well as the Livedoor shock hypothesis. Specifically, I estimate abnormal returns for each stock on its split announcement date and regress them on salient outcome variables. Results of these analyses demonstrate that (a) under the old stock split system, trading restrictions on newly issued shares caused increases in stock prices and (b) the Livedoor shock mitigated these split stock price increases. These results suggest that the stock split bubble burst not only because of stock split system reform, but also because of changes in investor sentiment related to split stocks.

To explore and describe these issues more comprehensively, I have organized the remainder of this study into a series of interrelated sections. In Section 2, I describe the Japanese stock-split system. Following this, I detail the effect of the Livedoor shock on split stocks in Section 3. In Section 4, I offer an account of the methods I employed and the results of my empirical analyses. Finally, in Section 5, I offer some concluding remarks.

\section{An Outline of the Japanese Stock-Split System}

In Japan, listed companies actively split their stocks to increase liquidity and the number of individual investors. The motivations for splitting stocks are two-fold. First, stock splitting has been facilitated by the October 2011 revisions in the Commercial Code (Note 9) and the "action program to promote lower stock investment units" in September of that same year. Market participants came to realize that stock splitting tended to increase stock prices on the date of the announcement, the ex-date, and in the subsequent days despite the fact that these announcements did not affect the company's fundamentals. This increase in the value of the company's stocks following the announcement of a stock split came to be known as the "stock split bubble."

Figure 2 illustrates the schedule of stock splits under the old system. This schedule applied to splits for which the base date (X) was before January 4, 2006. A base date refers to the date by which shareholders who are allotted stock splits must be determined. Note that shareholders who are allotted new shares maintain cum rights on the final trading day (X-4) because settlement shall be made on the fourth day following the final trading day with cum rights. Therefore, a person who holds stocks from the ex-date (the day following the final trading day with cum rights) has no right to receive new shares. However, even if stockholders with cum rights on the final trading day sell all their holdings on the ex-date, he/she still has the right to receive new shares. Following the ex-date, stocks trade at a lower price than on the previous day because a stock split dilutes stock value in accordance with split-ratios.

Under the old system, new shares could be delivered or traded on or after the pay-date (approximately 50 days 
after the base date), not the ex-date. As a result, market participants were only able to trade old stocks between the ex-date and the pay-date.

Figure 3 shows the stock split schedule under the revised system. This schedule is applied to splits for which the base date $(\mathrm{X})$ is on or after January 4, 2006. As a result of this revision, the pay-date is shifted from approximately 50 days after the base date to the ex-date (X-3). As a result of this change, market participants can trade new shares on the ex-date or the new pay-date, thereby alleviating restrictions that were in place under the old system.

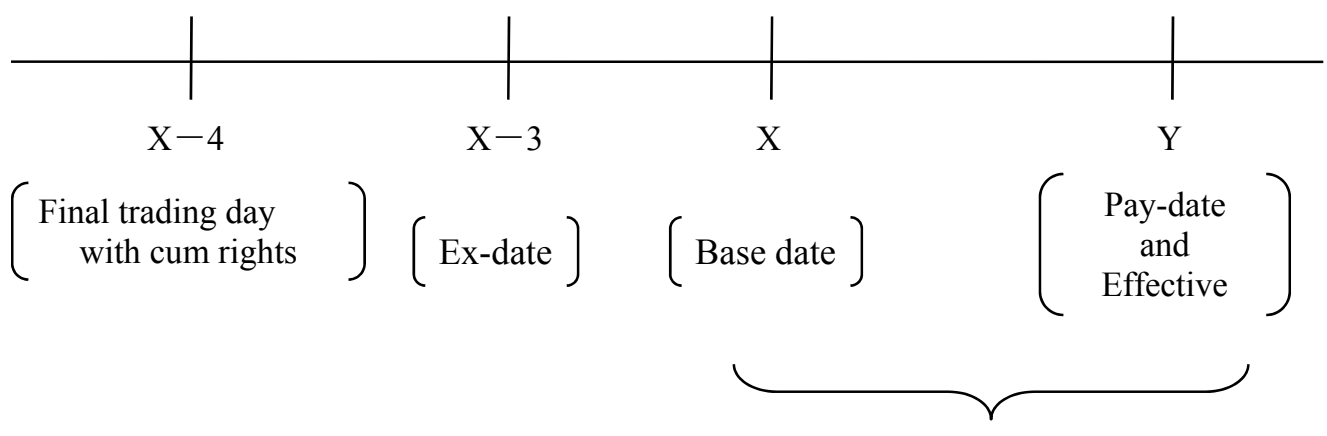

approximately 50 days

Figure 2. Schedule of the stock split on pre-revision (before 2006)

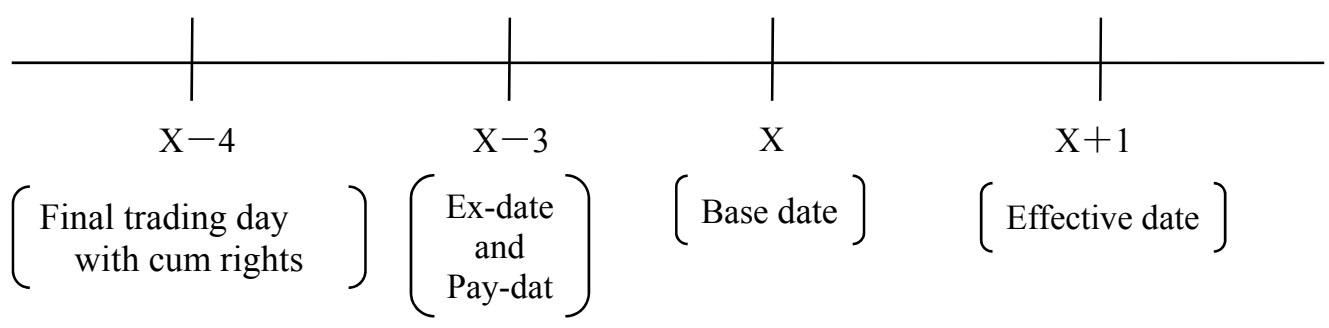

Figure 3. Schedule of the stock split on post-revision (after 2006)

\section{The Effect of the Livedoor Shock on Split Stocks}

In this paper, I argue that the Japanese stock split bubble burst not only because of the reformed stock split system, but also because of the negative effect of a criminal investigation on Livedoor stock. In this section, I discuss how the Livedoor shock negatively affected not only the prices of past split stocks, but also current split stocks.

Performing analyses to this end is problematic, given the identification of a valid sample to confirm the impetus behind the fall of Livedoor stock prices. If the sample includes stock split data under both the old and new systems, it may possibly interact with the other system on the day of the Livedoor shock.

If a sample is comprised of data related to pre-revision stock splits that did not have new issues on the date of the Livedoor shock, the value of the sample stocks on the date of the Livedoor shock may decrease before the pay-date. At this time, it is impossible to distinguish between the respective effects of the Livedoor shock and the delay of new issues under the old system. Therefore, when collecting data from before the system's revision, it is necessary to collect only that data related to stocks that split which have already issued new shares. In contrast, observations with ex-dates before the Livedoor shock, but after the system's revision include three companies. Given the small number of observations in my sample, it is necessary to utilize data that has been collected from split stocks that have been announced, but not completed, before the Livedoor shock.

The remainder of this section is dedicated to demonstrating that the Livedoor shock affects stock splits regardless of the stock split system in practice. To do so, I utilize two separate samples: pre-revision splits and post-revision splits. Pre-revision splits refer to those stock splits that were completely finished under the old system, but prior to the Livedoor shock (such as A-stocks). More specifically, the sample comprising 
pre-revision splits includes the splits for which the pay-day is between November 1, 2005, and December 31, 2005 , under the old system. Because this sample is comprised of exclusively pre-revision splits, they were affected by the Livedoor shock. The other sample is comprised of stocks for which their splits had already been announced, but had not been implemented under the new system prior to the Livedoor shock (referred to as B-stocks). Because they implemented the splits after the Livedoor shock, (Note 10) all stocks in this sample were subject to the regulations of the revised stock split system.

Table 1 displays the abnormal returns for A-stocks on the day of the Livedoor shock. The raw returns for all stocks were negative and had an average of $-4.19 \%$. Similarly, all adjusted abnormal returns (with the exception of two stocks) were negative; their average was $-2.36 \%$ (Note 11 ). The average standardized abnormal return was significant and negative at $-9.94 \%$. Taken together, these results indicate that the Livedoor shock significantly influenced the prices of stocks that split under the old system.

Table 1. Abnormal return of A-stocks on the date of the Livedoor shock

\begin{tabular}{cccc}
\hline Security Code & Actual Return & AR & SAR \\
\hline T2395 & $-6.94 \%$ & $-6.15 \%$ & -28.07 \\
T2674 & $-1.92 \%$ & $-0.78 \%$ & -4.31 \\
T3770 & $-13.19 \%$ & $-9.13 \%$ & -16.37 \\
T4082 & $-3.44 \%$ & $-0.97 \%$ & -3.85 \\
T4295 & $-4.53 \%$ & $-1.33 \%$ & -5.02 \\
T4464 & $-3.32 \%$ & $-3.09 \%$ & -21.74 \\
T4799 & $-0.33 \%$ & $0.67 \%$ & 3.28 \\
T6869 & $-1.92 \%$ & $0.83 \%$ & 4.88 \\
T7741 & $-3.13 \%$ & $-1.85 \%$ & -17.31 \\
T7867 & $-3.18 \%$ & $-1.79 \%$ & -10.91 \\
& $-4.19 \%$ & $-2.36 \%$ & -9.94 \\
& & t-value & $-31.44 * * *$ \\
\hline
\end{tabular}

Note. $* * * \mathrm{p}<.01$.

Table 2. Abnormal return of B-stocks on the date of the Livedoor shock

\begin{tabular}{cccc}
\hline Security Code & Actual Return & AR & SAR \\
\hline T2593 & $-0.26 \%$ & $1.76 \%$ & 11.64 \\
T2792 & $-2.16 \%$ & $-0.58 \%$ & -2.50 \\
T3387 & $-7.19 \%$ & $-8.17 \%$ & -10.95 \\
T3955 & $-1.04 \%$ & $-0.77 \%$ & -5.94 \\
T4722 & $0.38 \%$ & $2.34 \%$ & 8.95 \\
T5727 & $-3.62 \%$ & $-0.74 \%$ & -2.49 \\
T7616 & $-3.06 \%$ & $-2.72 \%$ & -13.18 \\
T8198 & $-0.80 \%$ & $-0.23 \%$ & -1.25 \\
T8519 & $-11.51 \%$ & $-10.74 \%$ & -59.79 \\
T8570 & $-1.00 \%$ & $1.07 \%$ & 7.79 \\
& $-3.03 \%$ & $-1.88 \%$ & -6.77 \\
& & t-value & $-21.42 * * *$ \\
\hline
\end{tabular}

Note. $* * * \mathrm{p}<.01$

Table 2 summarizes the abnormal returns for B-stocks on the day of the Livedoor shock. The raw returns for all stocks (except one) were negative. Their collective average was $-3.03 \%$. Like the A-stocks, the adjusted abnormal returns were largely negative and averaged $-1.88 \%$. The average standardized abnormal return was also significant and negative (-6.77\%). These results suggest that the Livedoor shock significantly affected stocks that split under the new system as well.

Because both samples were comprised of a small number of stocks $(\mathrm{N}=10)$ (Note 12), I used the market adjusted model to calculate the abnormal returns. Results of these calculations are listed in Table 3. The adjusted average returns for A-stocks and B-stocks were $-2.62 \%(\mathrm{t}=-21.25, \mathrm{p}<.01)$ and $-2.20 \%,(\mathrm{t}=-10.37, \mathrm{p}<.01)$. 
Taken in concert, these results suggest that the Livedoor shock significantly affected split stocks.

Table 3. Abnormal return on the date of the Livedoor shock using matching portfolio approach

\begin{tabular}{ccccc}
\hline & Observation & $\mathrm{AR}$ & $\mathrm{t}$ & \\
\hline A-stocks & 33 & $-2.62 \%$ & -21.25 & $* * *$ \\
B-stocks & 20 & $-2.20 \%$ & -10.37 & $* * *$ \\
\hline
\end{tabular}

Note. Abnormal returns are calculated by using a market adjusted model (deducting average return of the correspond sector). $* * * \mathrm{p}<.01$.

\section{Data and Empirical Method}

\subsection{Data}

The sample consisted of common stocks listed on Tokyo Stock Exchange (TSE) that split between October of 2001 and December of 2007 with a factor greater than 1.5-to-1. I retrieved data related to the stocks' ex-dates and pay-dates from the TSE and the stock split announcement dates from the Nihon Keizai Shimbun. To avoid the influence of variables other than the stock splits, I excluded stocks that yielded a dividend that changed from the announcement date to the pay-date. As a result of these inclusion and exclusion criteria, the final sample consisted of 189 stock split events. I obtained corresponding price and financial data from the Nikkei Economic Electronic Database System (NEEDs).

Table 4 illustrates the distribution of the 189 observations in terms of split factor across the various years between October of 2001 and December of 2007. As evidenced by Table 4, my sample is comprised of split events characterized by split factors that range from 1.5 to more than 10. Stock splits that are performed with split ratios of 1.5-for-1, 2-for-1, and 3-for-1 account for the vast majority of all splits in the sample (84.7\%). For the 2006 data, the figures in parentheses represent the number of split stocks for which splits had already been announced prior to the Livedoor shock. Ten stocks split under the new system and were announced before the Livedoor shock.

Table 4. Distribution of stock split by year and by factor

\begin{tabular}{|c|c|c|c|c|c|c|c|c|}
\hline \multirow[t]{2}{*}{ Year } & \multicolumn{8}{|l|}{ Split Factor } \\
\hline & 1.5 & 2 & 2.05 & 3 & 4 & 5 & $\geqq 10$ & Total \\
\hline 2001 & & 2 & & & & & & 2 \\
\hline 2002 & 1 & 5 & & & & 1 & 3 & 10 \\
\hline 2003 & 1 & 10 & & 1 & & & 1 & 14 \\
\hline 2004 & 3 & 29 & & 6 & 2 & 1 & 2 & 43 \\
\hline 2005 & 5 & 26 & 1 & 7 & 5 & 6 & & 50 \\
\hline 2006 & $6(4)$ & $30(4)$ & & $10(1)$ & $1(1)$ & 3 & & $50(10)$ \\
\hline 2007 & 2 & 14 & & 2 & & 3 & & 21 \\
\hline Total & $18(4)$ & $116(4)$ & 1 & $26(1)$ & 8 & 14 & 6 & $189(10)$ \\
\hline
\end{tabular}

Table 5 illustrates the frequency of stock splits by industry. The TSE classifies all listed companies into one of ten industries. As evidenced by Table 5, splits occur in 7 of these industries. Given that splits occur frequently in the manufacturing, transportation and communication, wholesale and retail, and service industries, Table 5 demonstrates that our data are essentially representative of all firms listed on the TSE.

Table 5. Industry distribution of sample stocks

\begin{tabular}{ll}
\hline Industry & Number of stocks \\
\hline Construction & 4 \\
Manufacturing & 54 \\
Transportation and Communication & 32 \\
Wholesale and Retail & 39 \\
Financial and Insurance & 6 \\
Real Estate & 16 \\
Service & 38 \\
Total & 189 \\
\hline
\end{tabular}


Table 6 summarizes the descriptive statistics associated with split stocks. The average raw return for stocks on the date on which their split is announced is $4.6 \%$. Pre-split turnover is based on the average daily turnover for the period between 135 business days prior to the announcement date and 16 business days prior to the announcement date. Post-split turnover is based on the average daily turnover during the 15-day period following the pay-date. Both turnovers are measured in millions of yen. In my measurement of post-split turnover, I did not include the securities if their outstanding stock volume on pay-date was changed from announcement date to pay-date except by stock split to avoid effects other than the stock split. The average post-split turnover falls below the average pre-split turnover. Stock splits are generally considered effective actions for promoting market liquidity, but this not may be the case here. Although they defined average daily volume following a stock split using the ex-date rather than the pay-date as a baseline, Guo, Zhou, and Cai (2008) reported a decrease in post-split volume on the Tokyo Stock Exchange between March 1996 and December 2005.

Table 6. Descriptive statistics for split stocks

\begin{tabular}{lllllll}
\hline & $\mathrm{N}$ & Mean & S.D. & Median & Min & Max \\
\hline Raw Return on Announcement Date & 189 & 0.046 & 0.081 & 0.034 & -0.159 & 0.413 \\
Pre-Split Turnover & 189 & 1.060 & 3.158 & 0.179 & 0.002 & 27.66 \\
Post-Split Turnover & 164 & 0.987 & 2.889 & 0.211 & 0.003 & 28.82 \\
Earnings Growth (-1) & 140 & 0.882 & 7.159 & 0.160 & -3.658 & 84.25 \\
Earnings Growth (0) & 157 & 0.729 & 6.748 & 0.182 & -4.590 & 84.25 \\
Earnings Growth (+1) & 170 & -0.093 & 1.626 & 0.049 & -13.162 & 5.636 \\
\hline
\end{tabular}

To represent the average growth rate of operating profit, $(-1),(0)$, and (-1) respectively represent the previous accounting period, the current accounting period, and the next accounting period. For instance, the average growth rate for the current accounting period was calculated by subtracting the operating profit rate during current period from the operating profit rate during the last period. The average growth rate during the previous accounting period was 0.882 . The average growth in period following a split is 0.729 . These results provide empirical support for the signaling hypothesis, indicating that a manager may split stocks if he/she anticipates an increase in the operational profit rate.

\subsection{The Calculation of Abnormal Return}

To calculate abnormal returns, I employed an event study methodology with a market model. An event study methodology calculates abnormal returns surrounding the date of an event date. In this paper, I follow Campbell, Lo, and MacKinlay (1997) to calculate abnormal returns. Specifically, I used the following market model:

$$
R_{i, t}=\alpha_{i}+\beta_{i} R_{m, t}+\varepsilon_{i, t}, \mathrm{E}\left[\varepsilon_{i, t}\right]=0, \operatorname{Var}\left[\varepsilon_{i, t}\right]=\sigma_{i}^{2}
$$

where $R_{i, t}$ and $R_{m, t}$ respectively indicate actual returns for security $i$ and market return on trading day $t . \varepsilon_{i, t}$ is an error term with average 0 and volatility $\sigma_{i}^{2}, \alpha_{i}, \beta_{i}$ and $\sigma_{i}^{2}$ are the parameters of the market model. For the purposes of the current study, the estimation window for the parameters was [-135, -16] trading days prior to the announcement of the stock split. I did not include a security if its outstanding stock volume changed from the date of the split announcement to the pay date (except by stock split). These securities were excluded to avoid any unforeseen effects caused by other events. For a market index, I utilized the value-weighted Tokyo Stock Exchange Section 1 index (TOPIX). Because I calculated abnormal returns as per equation (1), I calculated abnormal returns on event date $\mathrm{t}, \mathrm{A} R_{i, t}$ as follows:

$$
A R_{i, t}=R_{i, t}-\hat{\alpha}_{i}-\hat{\beta}_{i} R_{m, t}
$$

where $\hat{\alpha}_{i}$ and $\hat{\beta}_{i}$ are estimates of $\alpha_{i}$ and $\beta_{i}$, respectively. Using this equation, I calculated (a) the abnormal returns for the 15 days centered on the announcement date and (b) the standardized abnormal returns for each company while accounting for differences in security volatility (i.e., dividing the stock return by its corresponding standard deviation).

\subsection{Testable Hypotheses}

In this study, I seek to demonstrate the trading restriction hypothesis and the ways in which the Livedoor shock affected investor sentiment. To do so, I treat abnormal returns on the announcement date as the model's outcome variable. Moreover, there are three days that could be used as event dates related to the stock split: the 
announcement date, the ex-date, and the pay-date. I focus on abnormal returns on the announcement date because new expectations related to a stock split influence stock prices on that day. Although trading restrictions may affect a stock's price on its ex-date and pay-date, other factors unsatisfactorily explain the effect of investor expectations on stock price on those days. By treating abnormal returns on the announcement date as the outcome measure, it is possible to gauge changes in stock price and investor sentiments before and after the stock split system was revised.

To explore whether stock price is higher after that stock's pay-date relative to its announcement date (perhaps because of the Livedoor shock), it is necessary to compare stock returns from before the stock split announcement to those after the pay-date (but before the Livedoor shock). In addition, to identify and gauge the perpetual effect of the revised system with the Livedoor shock, it is necessary to compare the returns on the stock that implemented a split under the new system before the Livedoor shock, with the returns on the stock that implemented the split under the new system after the Livedoor shock. However, there are only three stocks that have been split under the new system before the Livedoor shock. As a result, the sample associated with this analysis is quite small, preventing my ability to test whether rising prices of split stocks were resolved by the Livedoor shock. Instead, I explore whether stock split announcements incite negative investor sentiment in the wake of the Livedoor shock.

To do so, I employ the following regression equation:

$$
\begin{aligned}
A R_{i} & =\text { const. }+\beta_{1} \cdot D_{i}+\beta_{2} \cdot D_{-} L S_{i}+\beta_{3} \cdot I L L_{i}+\beta_{4} \cdot D_{-} I L L_{i}+\beta_{5} \cdot T O_{i} \\
& +\beta_{6} \cdot D_{-} T O_{i}+\beta_{7} \cdot C E_{-} L 1_{i}+\beta_{8} \cdot C E_{-} 0_{i}+\beta_{9} \cdot C E_{-} 1_{i}+\beta_{10} \cdot A R_{-} T O_{i}+\varepsilon_{i}
\end{aligned}
$$

The dependent variable is the abnormal returns on the announcement date. $D$ is a dummy variable that equals one if the ex-date is after the stock split system was revised, and zero otherwise. $D_{-} L S$ is a dummy variable to indicate whether a stock split announcement occurred after the Livedoor shock; it equals one if the announcement date is after the Livedoor shock and zero otherwise. ILL signifies illiquidity (which is calculated with equation (3) below). $D \_I L L$ is an interaction term that incorporates $D$ and $I L L$. TO represents turnover with a relaxed trading restriction. $D_{-} T O$ is an interaction term that is comprised of $D$ and $T O$. $C E \_L 1, C E_{-} O$, and $C E \_1$ represent operating profit growth rate during the last accounting period, the current accounting period, and the next accounting period, respectively. Finally, $A R_{-} T O$ signifies the growth rate of daily average turnover for the period before the split announcement and after the pay-date.

The trading restriction hypothesis dictates that abnormal returns occur because of a stock's temporary illiquidity resulting from a stock split under the old system. I predict that there will exist a positive relationship between the magnitude of trading restrictions (ILL) and abnormal returns. Following Greenwood (2009), we define:

$$
\text { Trading Restrection }(I L L)=(1-1 / \text { split factor }) \times \text { Turnover }(T O)
$$

On the right-hand side, (1-1/split factor) indicates the proportion of total outstanding stock that is temporarily untradeable following the stock split. Multiplying by the average turnover allows for the estimation of a predicted loss of turnover under trading restrictions.

In addition, I examine the degree to which stock splits affect investor sentiment. It is possible that psychological effects are not proportional to trading restrictions. If investor expectations related to price increases disappear following the revision of the stock split system, we would expect the revision of the system to mitigate the relationship between positive investor sentiments and stock price.

To study this effect, I incorporate a dummy variable to represent whether a stock split after the system was revised $(D)$. If a stock's price increases as a result of investor sentiment, but this effect is mitigated by the system's revision, then the effect of $D$ on stock price is negative.

Note that while $D$ is assigned on the basis of the ex-date, the dependent variable is the abnormal return on the announcement date. Although these dates differ, the ex-date affects the stock price at the announcement date regardless of when the ex-date occurs. This is because on the announcement date, investors are aware of whether the split will take place under the new system or the old system by the ex-date.

The trading restriction hypothesis suggests that under the old system (but not the new system), ILL affects stock returns on the announcement date. As such, one would expect that the coefficient associated with $D \_I L L$ will be opposite to (and largely cancel out) the coefficient associated with $I L L$ under the new system. Therefore, I expect that $\beta_{3}>0$ and that $\beta_{3}=-\beta_{4}$.

Greenwood (2009) argued that turnover (TO) serves to relax trading restrictions. I predict that there will exist an inverse relationship between pre-split turnover and the effect of trading restrictions that result from the stock 
split. As a result, stock prices can be suppressed. Moreover, I expect turnover to exert a negative effect on stock price. As with $I L L$, we expect this effect to disappear following the revision of the stock split system. Therefore, I expect the coefficient of $D_{-} T O$ to offset the coefficient for $T O$ under the new system. As such, I believe that $\beta_{5}$ $<0$ and $\beta_{5}=-\beta_{6}$.

Next, we consider the Livedoor shock hypothesis, which states that investor expectations of rising prices due to a split stock disappeared because of the Livedoor shock in January of 2006. If this prediction is true, price increases that would materialize on the announcement date would disappear following the Livedoor shock. To explore this possibility, I developed a dummy variable $\left(D_{-} L S\right)$ to indicate whether a split was announced before or after the Livedoor shock. $D_{-} L S$ equals one if the split announcement was made after the Livedoor shock and zero otherwise. If price increase expectations caused by a stock split are disappear after the Livedoor shock, then the effect of $D_{-} L S$ on stock price should be negative (i.e., $\beta_{2}<0$ ).

In addition to the above, I test the validity of the signaling and liquidity hypotheses. The signaling hypothesis dictates that the market reacts positively to split announcements. To test this possibility, I employ operating profit during the last accounting period ( $\left.C E_{-} L 1\right)$, the current accounting period $\left(C E_{-} O\right)$, and the next accounting period $\left(C E_{-} I\right)$ as predictor variables. I expect each of these variables to positively influence stock price (i.e., $\beta_{7}>0, \beta_{8}>$ 0 , and $\beta_{9}>0$ ).

To test the liquidity hypothesis, I utilize the daily average turnover growth rate from the period before the split announcement to after the pay-date as a predictor $\left(A R_{-} T O\right)$. More specifically, I utilize a growth rate that divides the average turnover between the pay-date and after $1 \overline{5}$ business days by the average turnover. I expect this effect to improve liquidity and exert a positive effect on stock price $\left(\beta_{10}>0\right)$ (Note 13).

\section{Empirical Results}

Table 7 reports the results of the estimation of equation (4). Model 1 contains the results of a regression analysis that incorporated all explanatory variables. The coefficient for $I L L\left(\beta_{3}\right)$ was $4.717(\mathrm{t}=2.67, \mathrm{p}<.001)$. The test of the coefficient condition $\left(\beta_{3}=-\beta_{4}\right)$ is not rejected by an F-test (Note 14). This result suggests that the rule revision canceled out only the increased price under the old system. Taken together, these results provide support for the trading restriction hypothesis.

In addition, the coefficient for $T O$ indicates that it is a negative predictor of abnormal returns. The test of the coefficient condition $\left(\beta_{5}=-\beta_{6}\right)$ is not rejected by an F-test. This result means that, after the revision, the pre-split turnover has no effect for the price of split stock. It also supports the trading restriction hypothesis. The coefficient for $D$ indicates that whether a stock split occurred after the revision of the stock split system is not a significant predictor of abnormal returns, suggesting that the revision of the stock split system did mitigate expectations that stock prices would rise as a result of a stock split. Results also showed $D_{-} L S$ to be a significant, negative predictor of abnormal returns. This indicates that the disappearance of the stock split bubble after 2006 is attributable not only to the revision of the stock split system, but also to the criminal investigation of Livedoor and associated fallout across the TSE.

Coefficients associated with the variables for operating profit ( $C E_{-} L 1, C E_{-} 0$, and $\left.C E_{-} 1\right)$ were non-significant, and fail to support the signaling hypothesis. Similarly, the coefficient for the growth rate of turnover $\left(A R_{-} T O\right)$, which serves as a proxy for improving liquidity, is also non-significant. As such, our results also fail to support the liquidity hypothesis.

$$
\begin{aligned}
A R_{i} & =\text { const } \cdot+\beta_{1} \cdot D_{i}+\beta_{2} \cdot D_{-} L S_{i}+\beta_{3} \cdot I L L_{i}+\beta_{4} \cdot D_{-} I L L_{i}+\beta_{5} \cdot T O_{i} \\
& +\beta_{7} \cdot C E_{-} L 1_{i}+\beta_{8} \cdot C E_{-} 0_{i}+\beta_{9} \cdot C E_{-} 1_{i}+\beta_{10} \cdot A R R_{-} T O_{i}+\varepsilon_{i}
\end{aligned}
$$

\begin{tabular}{|c|c|c|c|c|c|c|c|c|c|}
\hline & \multicolumn{3}{|c|}{ Model 1} & \multicolumn{3}{|c|}{ Model 2} & \multicolumn{3}{|c|}{ Model 3} \\
\hline & coef. & $\mathrm{t}$ & & coef. & $\mathrm{t}$ & & coef. & $\mathrm{t}$ & \\
\hline $\mathrm{D}$ & 1.494 & 1.38 & & 1.022 & 0.93 & & 1.021 & 1.05 & \\
\hline D_LS & -2.98 & -2.78 & $* * *$ & -2.377 & -2.11 & $* *$ & -2.416 & -2.45 & $* *$ \\
\hline ILL & 4.717 & 2.67 & $* * *$ & 4.829 & 3.13 & $* * *$ & 4.561 & 2.64 & $* * *$ \\
\hline D_ILL & -4.366 & -2.26 & $* *$ & -4.598 & -2.59 & $* *$ & -4.152 & -2.2 & $* *$ \\
\hline TO & -3.814 & -2.72 & $* * *$ & -3.97 & -3.28 & $* * *$ & -3.691 & -2.7 & $* * *$ \\
\hline D_TO & 3.63 & 2.44 & $* *$ & 3.804 & 2.84 & $* * *$ & 3.477 & 2.4 & $* *$ \\
\hline CE L1 & 0.024 & 0.75 & & & & & 0.027 & 0.88 & \\
\hline
\end{tabular}

Table 7. Cross-sectional regression results for the abnormal return on announcement date 


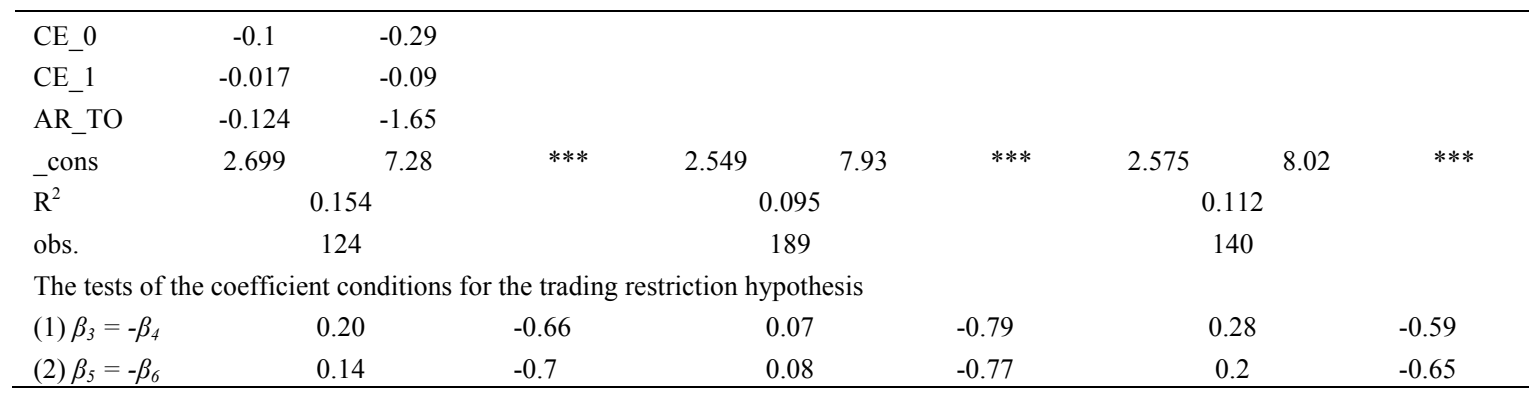

Table 7. Continued

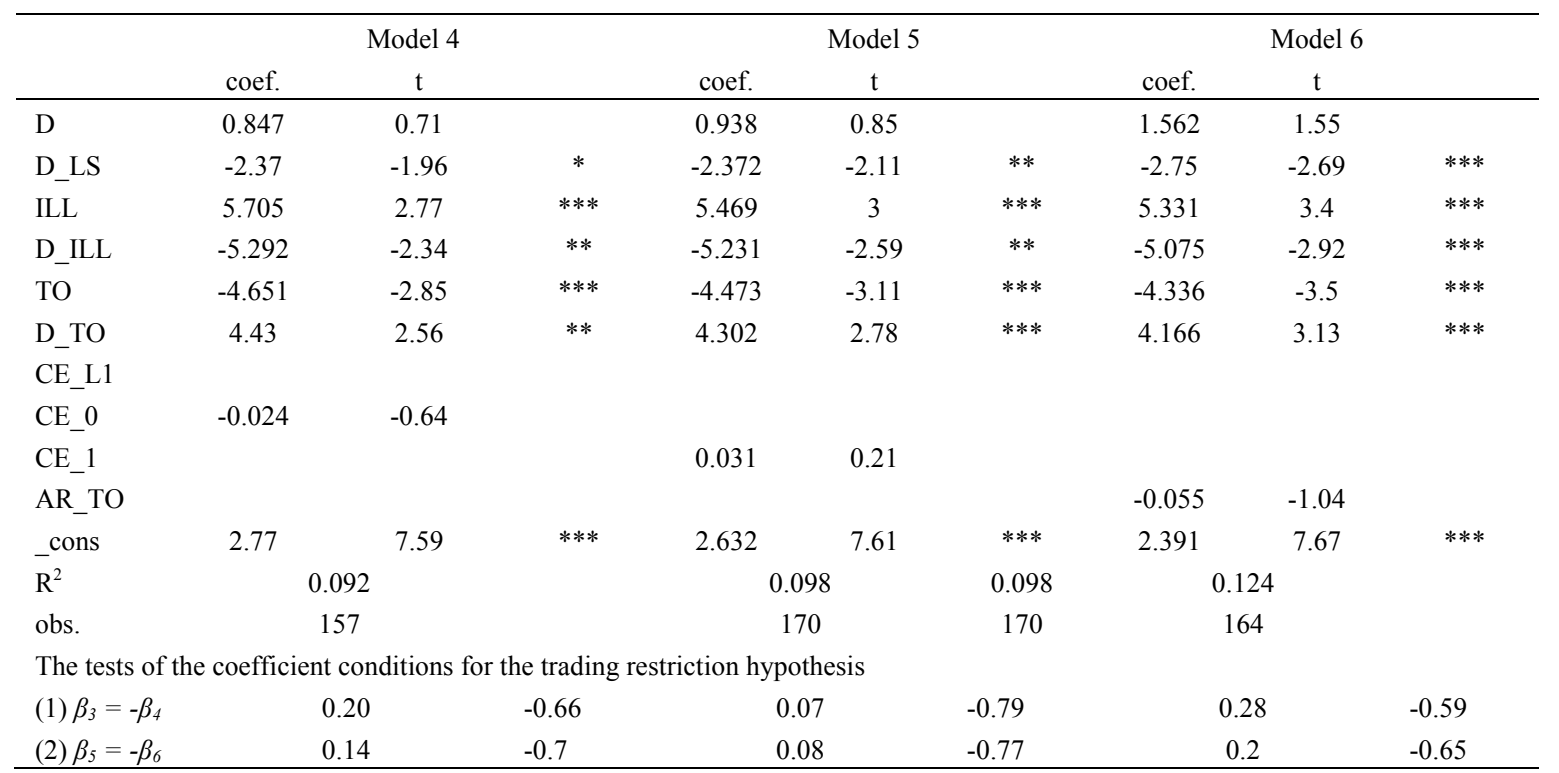

Note. The test statistics of the coefficient conditions are the $\mathrm{F}$ statistics. P-values are in parentheses.

$* * * \mathrm{p}<.01, * * \mathrm{p}<.05, * \mathrm{p}<.10$.

That our results have failed to support the signaling or liquidity hypotheses could be overshadowed by a correlation among the three variables related to operating profit growth rate and turnover. Given this, I utilize each of these variables separately for inclusion in the regression analysis. The results of these analyses are respectively presented as Models 3 through 6. Despite analyzing them separately, none of the results support the signaling or liquidity hypotheses. That said, all results of all regression analyses support the trading restriction and the Livedoor shock hypotheses. Model 2 is related to the regression analysis in which all variables related to the signaling and liquidity hypotheses were excluded. These results are robust, thereby providing consistent support for the trading restriction and the Livedoor shock hypotheses (Note 15).

\section{Conclusion}

In Japan, stock splits became an increasingly popular strategy after 2001. While stock splits grew in popularity, prices of those split stocks increased at the announcement date and ex-date. Post-pay-date stock prices were also substantially higher than pre-announcement stock prices. Taken together, these phenomena comprise what has become known as the "Stock Split Bubble."

Foremost, in this paper, I demonstrated that the Livedoor affair not only decreased the price of Livedoor-related companies, but also the prices of stocks that had split in the past as well as those that split contemporarily. In addition, I have used data that compounds pre-revision and post-revision stock prices to provide support for the trading restriction hypothesis. Results show that the trading restrictions contributed to the formation of the bubble before the stock split system was revised, but had no effect on stock prices following the changes to the stock split system. Further, our data provided no empirical support for the signaling or liquidity hypotheses. Perhaps more importantly, our results showed that although revisions to the stock split system may have contributed to the destruction of the stock split bubble to some degree, the Livedoor affair was also a 
contributing element to the burst.

In summary, our analyses have provided empirical support for the trading restriction and Livedoor shock hypotheses, but not the signaling or liquidity hypotheses. Despite these findings, methodological shortcomings associated with our analyses restrict the degree to which I can definitively conclude that the latter two hypotheses have no merit. If data are available, it may be useful to utilize the difference between corporate earnings at split announcements that were forecast by managers or analysts and actual earnings as the predictor of the signaling hypothesis. In addition, it may similarly be useful to utilize the number of shareholders to test the liquidity hypothesis. In short, future research should employ more complex and comprehensive methods to more definitively support or refute the signaling and liquidity hypotheses.

\section{References}

Amihud, Y., \& Mendelson, H. (1986). Asset pricing and the bid-ask spread. Journal of Financial Economics, 17, 223-249. http://dx.doi.org/10.1016/0304-405X(86)90065-6

Amihud, Y., Mendelson, H., \& Pedersen, L. H. (2006). Liquidity and asset prices. Foundations and Trends in Finance, 1, 269-364. http://dx.doi.org/10.1561/0500000003

Amihud, Y., Mendelson, H., \& Uno, J. (1999). Number of shareholders and stock prices: Evidence from Japan. Journal of Finance, 54, 1169-1184. http://dx.doi.org/10.1111/0022-1082.00141

Asquith, P., Healy, P., \& Palepu, K. (1989). Earnings and stock splits. Accounting Review, 64, 387-403.

Campbell, J. Y., Lo, A. W., \& MacKinlay, A. C. (1997). The econometrics of financial markets. Princeton, NJ: Princeton University Press. http://dx.doi.org/10.1017/S1365100598009092

Chen, J., Hong, H., \& Stein, J. C. (2002). Breadth of ownership and stock returns. Journal of Financial Economics, 66, 171-205. http://dx.doi.org/10.1016/S0304-405X(02)00223-4

D'Avolio, G. (2002). The market for borrowing stock. Journal of Financial Economics, 66, 271-306. http://dx.doi.org/10.1016/S0304-405X(02)00206-4

Diamond, D. W., \& Verrecchia, R. E. (1987). Constraints on short-selling and asset price adjustment to private $\begin{array}{lllll}\text { information. Journal of } & \text { Financial }\end{array}$ http://dx.doi.org/10.1016/0304-405X(87)90042-0

Duffie, D., Garleanu, N., \& Pederson, L. (2002). Securities lending, shorting, and pricing. Journal of Financial Economics, 66, 307-339. http://dx.doi.org/10.1016/S0304-405X(02)00226-X

Fama, E., Fisher, L., Jensen, M. C., \& Roll, R. (1969). The adjustment of stock prices to new information. International Economic Review, 10, 1-21. http://dx.doi.org/10.2307/2525569

Greenwood, R. (2009). Trading restrictions and stock prices. Review of Financial Studies, 22, 509-539. http://dx.doi.org/10.1093/rfs/hhn022

Guo, F., Zhou, K., \& Cai, J. (2008). Stock splits, liquidity, and information asymmetry: An empirical study on Tokyo Stock Exchange. Journal of the Japanese and International Economies, 22, 417-438. http://dx.doi.org/10.1016/j.jjie.2008.01.002

Hanaeda, H., \& Serita, T. (2004). The effects of stock splits on stock prices, liquidity, and stock ownership: Evidence from Japan. Working Paper, Hitotsubashi University.

Kothari, S., \& Warner, J. (2007). Econometrics of event studies. In B. E. Eckbo (Ed.), Handbook of empirical corporate finance. New York: Elsevier. http://dx.doi.org/10.1016/B978-0-444-53265-7.50015-9

Kuse, Y., \& Yamamoto, T. (2008). Stock price anomalies subsequent to stock split announcements: Japanese evidences. Retrieved February 20, 2014, from http://dx.doi.org/10.2139/ssrn.1101210

Lakonishok, J., \& Lev, B. (1987). Stock splits and stock dividends: Why, who, and when. Journal of Finance, 42, 913-932. http://dx.doi.org/10.2307/2328298

Merton, R. C. (1987). A simple model of capital market equilibrium with incomplete information. Journal of Finance, 42, 483-510. http://dx.doi.org/10.2307/2328367

Miller, E. (1977). Risk, uncertainty, and divergence of opinion. Journal of Finance, 32, 1151-1168. http://dx.doi.org/10.2307/2326520

McNichols, M., \& Dravid, A. (1990). Stock dividends, stock splits, and signaling. Journal of Finance, 45, 857879. http://dx.doi.org/10.2307/2328796 
Tversky, A., \& Kahneman, D. (1974). Judgment under uncertainty: Heuristics and biases. Science, 185, 11241131. http://dx.doi.org/10.1126/science.185.4157.1124

\section{Notes}

Note 1 . The signaling hypothesis also represents a possible explanation as to why managers execute stock splits. The signaling hypothesis suggests that managers declare stock splits to communicate positive information related to the future prospects of his/her company.

Note 2. The second hypothesis implies an increase of liquidity after pay-day; the third and fourth hypotheses imply a decrease in liquidity before pay-date.

Note 3. The influence of such a restriction on stock price is comparable to the influence of short selling regulations, as stock prices are more affected by investors with optimistic private information, even if information related to the future value of a stock is normally distributed (Miller, 1977). Several researchers (see Chen, Hong, and Stein, 2002; D'Avolio, 2002; Diamond and Verrecchia, 1987; Duffie, Gârleanu, and Pederson, 2002) have suggested that stock prices do not necessarily reflect the outlooks of traders who are pessimistic or have private information related to the overvaluing of a stock.

Note 4. Horie Takafumi was arrested for violating the Securities and Exchange Act. He was convicted of account rigging in April of 2011.

Note 5. At the time of the Livedoor shock, there were 606,338,627 total outstanding units of Livedoor. This accounted for roughly $45 \%$ of all units listed on the Tokyo Stock Exchange. Therefore, a rush of sell orders for Livedoor stock incited a breakdown in the TSE trading system by exceeding its capacity for daily orders.

Note 6. This behavior can be explained by the "representativeness heuristic" (Tversky \& Kahneman, 1974). Until 2005, a stock split represented an increase in stock price, which was considered good news by investors. However, following the Livedoor shock in January of 2006, a stock split came to represent a company's poor performance.

Note 7. In its January 17, 2006 evening edition, the Nihon Keizai Shimbun reported the sliding price of a company that split in the past, indicating that market participants have largely focused interest on companies relative to stock splits following the Livedoor-shock .

Note 8 . Additionally, my sample is smaller than Greenwood's because I collected 1.5 -for-1 split events after October 2001, when the Commercial Code revised.

Note 9. In the revision of the Commercial Code, the net assets per value regulation was abolished, and the unit stock system was introduced, making it possible for issuing companies to set the stock investment unit freely and flexibly by a resolution at a board of directors meeting.

Note 10. I also considered creating another sample comprised of stocks that implement splits under the revised system prior to the Livedoor shock. However, only three companies would have provided valid data for this time frame. Given that these data would have been insufficient for hypothesis testing, this sample was not created.

Note 11. I explain the method for calculating abnormal returns using the market model in the following section.

Note 12. Kothari and Warner (2007) reported that the statistical power associated with these tests is sufficiently high given that the event window is only one day. Therefore, any issues related to sample size are likely minimal.

Note 13. As a proxy for liquidity, I used traded volume rather than turnover. However, I found that this proxy had no significant influence on abnormal returns. I additionally used dummies to respectively indicate whether a stock was from the information-communications industry or a venture startup. Neither of these dummies had a significant effect on abnormal returns.

Note 14. This statistic is calculated such that $F=(R S S R-U S S R / r) /(U S S R / n-k-1)$ where $R S S R$ is the restricted sum of squared residuals, USSR is the unrestricted sum of squared residuals, $n$ is the number of observations, $k$ is the number of explanatory variables, and $r$ is the number of restrictions (in this case, $r=1$ ). This $\mathrm{F}$ statistic is distributed as $F(r, n-k-1)$. For the test of the restriction that $\beta_{3}=-\beta_{4}$, I used the restricted sum of squared residuals from the following restricted regression model:

$$
\begin{aligned}
A R_{i} & =\text { const. }+\beta_{1} \cdot D_{i}+\beta_{2} \cdot D_{-} L S_{i}+\beta_{3} \cdot I \tilde{L} L_{i}+\beta_{5} \cdot T O_{i}+\beta_{6} \cdot D_{-} T O_{i}+ \\
& +\beta_{7} \cdot C E_{-} L 1_{i}+\beta_{8} \cdot C E_{-} 0_{i}+\beta_{9} \cdot C E_{-} 1_{i}+\beta_{10} \cdot A R_{-} T O_{i}+\varepsilon_{i}
\end{aligned}
$$


where $I \widetilde{L} L$ equals $I L L$ if the ex-date is after the system revision and zero otherwise. For the test of the restriction such that $\beta_{5}=-\beta_{6}$, I used the restricted sum of squared residuals from the following restricted regression model:

$$
\begin{aligned}
A R_{i}= & \text { const }+\beta_{1} \cdot D_{i}+\beta_{2} \cdot D_{-} L S_{i}+\beta_{3} \cdot I L L_{i}+\beta_{4} \cdot D_{-} I L L_{i}+\beta_{5} \cdot \tilde{T O}{ }_{i} \\
& +\beta_{7} \cdot C E_{-} L 1_{i}+\beta_{8} \cdot C E_{-} 0_{i}+\beta_{9} \cdot C E_{-} 1_{i}+\beta_{10} \cdot A R_{-} T O_{i}+\varepsilon_{i}
\end{aligned}
$$

where $T O$ equals $T O$ if the ex-date is after the system revision and zero otherwise.

Note 15. I also separately tested the signaling and liquidity hypotheses during pre-revision and post-revision periods. To do so, I used interaction terms that incorporated $D$ and $C E_{-} L 1, C E_{-} 0, C E_{-} 1$, and $A R \_T O$, separately. None of the results associated with these analyses provided empirical support for the hypotheses.

\section{Copyrights}

Copyright for this article is retained by the author(s), with first publication rights granted to the journal.

This is an open-access article distributed under the terms and conditions of the Creative Commons Attribution license (http://creativecommons.org/licenses/by/3.0/). 